Pacific Journal of Mathematic 


\title{
A COMMON FIXED POINT THEOREM FOR NESTED SPACES
}

\author{
R. E. SMITHSON
}

Let $X$ be an arcwise connected Hausdorff space in which the union of any nest of arcs is contained in an arc. Let $f, g: X \rightarrow X$ be commuting functions (not necessarily continuous), which satisfy (1) $f(A)$ and $g(A)$ are arcwise connected for each arc $A \subset X$, and (2) $f^{-1}(x)$ and $g^{-1}(x)$ are arcwise connected for each $x \in X$. The principal result of this paper is:

THeOREM. The functions $f$ and $g$ have a common fixed point.

A space satisfying the conditions on $X$ is called a nested space. Functions which satisfy condition (1) are called arc preserving and those satisfying condition (2) are called strongly monotone. In [3] Harris showed that continuous functions are arc preserving. Thus we have:

CoRollary. Two commuting, continuous strongly monotone selfmaps of a nested space have a common fixed point.

In this context an arc is a continuum with exactly two noncutpoints. If $X$ is metrizable, then this coincides with the classical definition of an arc as the homeomorphic image of the closed unit interval.

Before proceeding to the proof of the main result we give an example which shows that an arc preserving, strongly monotone function is not necessarily continuous and then give a few historical remarks.

ExAMPLE. Let $X_{0}=\{(x, 0): 0 \leqq x \leqq 2\}$ and $X_{n}=\{(1 / n, y): 0 \leqq y \leqq 1\}$ for $n \geqq 1$. Next set $X_{-1}=\{(2, y): 0 \leqq y \leqq 2\}, X_{-2}=\{(x, 2): 0 \leqq x \leqq 2\}$ and $X_{-3}=\{(0, y): 1 \leqq y \leqq 2\}$. Then set $X=\cup\left\{X_{k}: k \geqq-3\right\}$. Define $f: X \rightarrow X$ by $f(z)=(2,0)$ if $z \in \bigcup_{i=1}^{3} U_{-i}$ and $f(z)=z$ otherwise. We see that $f$ is arc preserving and strongly monotone but $f$ is not continuous.

In 1967 W. J. Gray [1] proved that an abelian semigroup of continuous, monotone functions on an hereditarily unicoherent, hereditarily decomposable continuum into itself had a common fixed point. Further, in 1975 Gray and Smith [2] proved an extension of this result for hereditarily unicoherent, arcwise connected con- 
tinua. In this note we prove a common fixed point theorem for commuting functions on a nested space.

The notion of a nested space was used by G.S. Young [6] in 1946. In [6] Young showed that nested spaces have the fixed point property for continuous selfmaps. This theorem was subsequently extended to multifunctions by Smithson [5] and further extended by Muenzenberger and Smithson in [4].

REMARK. It is clear from the definition that a nested space is acyclic. Thus if $x, y \in X$ where $X$ is a nested space, we denote the unique arc in $X$ with endpoints $x, y$ by $[x, y]$. In the sequel $X$ will denote a nested space, and the functions $f, g$ satisfy conditions (1) and (2).

We define a partial order on $X$ as follows: Let $e \in X$. Then $x \leqq y$ if and only if $x \in[e, y]$. The proof that $\leqq$ is a partial order is routine and is omitted. In the remainder of the paper we assume that $X$ has this partial order.

LEMMA 1. The partial order $\leqq$ satisfies the following:

(i) If $x<y$, then there is a such that $x<z<y$.

(ii) If $C \subset X$ is totally ordered and nonempty, then sup $C$ exists in $X$.

(iii) For each $x, y \in X$, inf $\{x, y\}=x \Lambda y$ exists.

Proof. For (i) let $z \in[x, y]-\{x, y\}$. Then $z \in[x, y] \subset[e, y]$ since $x \in[e, y]$ and thus $x<z<y$. For (ii) note that $\{[e, c]: c \in C\}$ is a nested collection of arcs in $X$ and so $C$ is contained in an $\operatorname{arc}[e, a]$. Let $c_{0}=\sup C$ in $[e, a]$. If $C \subset[e, b]$, then $C \subset[e, a] \cap[e, b]$ which is an arc and so $c_{0} \leqq b$. Thus $c_{0}=\sup C$ in $X$. For (iii), let $A=$ $[e, x] \cap[e, y]$. Then $A$ is an arc $[e, a]$ and $a=x A y$.

REMARK. We could also show that each nonempty subset of $X$ has an infimum in $X$ and that for each $x \in X$, there is a maximal element $m \in X$ with $x \leqq m$.

If $x, y$ are not comparable, $x \Lambda y$ is a cutpoint of the arc $[x, y]$ and thus $[x, y]=[x \Lambda y, x] \cup[x \Lambda y, y]$.

Define the sets $L(x)$ and $M(x)$ by: $L(x)=\{y \in X ; y \leqq x\}$ and $M(x)=\{y: x \leqq y\}$. Then, since $L(x)=[e, x], L(x)$ is totally ordered. Also $M(x)$ is arcwise connected. We have:

LemMa 2. If $A$ is arcwise connected, if $A \cap M(x) \neq \phi \neq A \cap(X-$ $M(x))$, then $x \in A$.

Proof. Let $y_{1} \in A \cap M(x)$ and $y_{2} \in A \cap(X-M(x))$. Then $y_{1} A y_{2} \notin$ 
$M(x)$, but $y_{1} \Lambda y_{2} \in L\left(y_{1}\right)$. Thus $x \in\left[y_{1} \Lambda y_{2}, y_{1}\right] \subset\left[y_{1}, y_{2}\right] \subset A$.

Lemma 3. If $a<b$ and if $[a, b]$ contains a fixed point of $f$, then $x_{0}=\inf \{x \in[a, b]: f(x)=x\}$ is a fixed point of $f$. Hence, $[a, b]$ contains a smallest (in $[a, b])$ fixed point of $f$.

Proof. Let $x_{1} \in[a, b]$ be a fixed point of $f$. Then if $f\left(x_{0}\right) \neq x_{0}$, $x_{0}<x_{1}$ and we may assume that $f\left(x_{0}\right) \not x_{1}$. Let $z_{0}=f\left(x_{0}\right) \Lambda x_{1}$. Since $f$ is arc preserving, there is a $z_{1} \in\left[x_{0}, x_{1}\right]$ such that $f\left(z_{1}\right)=z_{0}$. Note $z_{1} \neq x_{0}$. Now let $x_{2}$ be a fixed point of $f$ such that $x_{0}<x_{2}<z_{1}$. Since $x_{2}<x_{1}, f\left(x_{0}\right) \Lambda x_{2} \leqq f\left(x_{0}\right) \Lambda x_{1} \leqq f\left(x_{0}\right)$. But $x_{2}$ and $f\left(x_{0}\right)$ are elements of $f\left[x_{0}, x_{2}\right]$ and thus so are $f\left(x_{0}\right) \Lambda x_{2}$ and $f\left(x_{0}\right)$. Hence, $z_{0} \in f\left[x_{0}, x_{2}\right]$. This implies that $f^{-1}\left(z_{0}\right) \cap M\left(x_{2}\right) \neq \varnothing$ and $f^{-1}\left(z_{0}\right) \cap\left(X-M\left(x_{2}\right)\right) \neq \varnothing$ and thus $x_{2} \in f^{-1}\left(z_{0}\right)$ since $f$ is strongly monotone. This is a contradiction to $f\left(x_{2}\right)=x_{2}$ and $x_{2}<z_{0}$.

Next we need another definition.

Definition. Let $a \in X$. The branch at a containing $x_{1} \in M(a)-a$ is the set $B=\left\{x: a<x \Lambda x_{1}\right\}$.

Thus if $B_{1}, B_{2}$ are two different branches at $a$ and if $x_{i} \in B_{i}$, $i=1,2$, then $a=x_{1} \Lambda x_{2}$ and $a \in\left[x_{1}, x_{2}\right]$.

Before proving the main result we need two more lemmas.

Lemma 4. If $A \subset X$ is a nonempty totally ordered set such that $x \leqq f(x)$ for $x \in A$, then, $x_{0} \leqq f\left(x_{0}\right)$ where $x_{0}=\sup A$.

Proof. Suppose $f\left(x_{0}\right) \notin M\left(x_{0}\right)$. Let $b=f\left(x_{0}\right) \Lambda x_{0}$ and let $b \leqq c \leqq x_{0}$. Since $x_{0}=\sup A$, there is an $x_{1}, c<x_{1}<x_{0}$, such that $x_{1} \leqq f\left(x_{1}\right)$. Then $f\left[x_{1}, x_{0}\right]$ meets $M(c)$ and $X-M(c)$ and hence, contains $c$. Let $z_{1} \in\left[x_{1}, x_{0}\right]$ with $f\left(z_{1}\right)=c$. Next let $x_{2}$ be in $A$ with $z_{1}<x_{2}<x_{0}$. Then $f\left[x_{2}, x_{0}\right]$ meets both $M(c)$ and $X-M(c)$ and also contains $c$. But then $f^{-1}(c)$ meets $M\left(x_{2}\right)$ and $X-M\left(x_{2}\right)$ and therefore contains $x_{2}$. This contradicts the choice of $x_{2}$. Thus $x_{0} \leqq f\left(x_{0}\right)$.

Lemma 5. Let $a<f(a)$. (i) If $B$ is the branch at a containing $f(a)$, then $B$ contains a fixed point of $f$. (ii) If $f(f(a)) \notin M(f(a)$ ), then $X-M(f(a))$ contains a fixed point of $f$.

Proof. For part (i) first let $a<x<f(a)$. Then if $f(x) \notin M(x)$, $f[a, x]$ contains $x$. Hence, there is an $x, a<x<f(a)$, with $x \leqq f(x)$. Now let $C$ be a maximal totally ordered set containing $x$ such that $c \leqq f(c)$ for all $c \in C$. Let $x_{0}=\sup C$. Then $f\left(x_{0}\right) \in M\left(x_{0}\right)$ follows from Lemma 4. Note that $x_{0}$ is in the branch at a containing $f(a)$. 
For $x_{0}<x_{1}<f\left(x_{0}\right), f\left(x_{1}\right) \notin M\left(x_{1}\right)$. Thus $x_{0} \in f\left[x_{0}, x_{1}\right]$. Suppose $f\left(z_{1}\right)=$ $x_{1}$ where $x_{0}<z_{1}<x_{1}$. But then $z_{1} \in C$ which contradicts the definition of $x_{0}$ and $C$. Thus $f\left(x_{0}\right)=x_{0}$.

For statement (ii) set $X_{0}=\{X-M(f(a))\} \cup\{f(a)\}$, and define $g: X_{0} \rightarrow X_{0}$ by $g(x)=f(x)$ if $f(x) \notin M(f(a))$ and $g(x)=f(a)$ if $f(x) \in$ $M(f(a))$. Since $X-M(f(a))$ is arcwise connected, $X_{0}$ is a nested space and $g$ is arc preserving, and strongly monotone. Now let $C$ be a maximal totally ordered set in $X_{0}$ which contains $a$ such that $x \leqq f(x)$ for all $x \in C$. Then let $x_{0}=\sup C$. (We are using $\leqq$ restricted to $X_{0}$.) From the hypothesis for (ii) $f(f(a)) \notin M(f(a))$ and thus $x_{0} \neq f(a)$. Then by the same argument used in part (i), $f\left(x_{0}\right)=$ $x_{0}$ and part (ii) follows.

Now we give the proof of the main theorem.

Proof. Let $A=\{x \in X: x \leqq f(x)$ and $x \leqq g(x)\}$ and let $C$ be a maximal totally ordered subset of $A$. Set $a=\sup C$. Then by applying Lemma 4 to $f$ and $g$ we see that $a \in C$. The remainder of the proof is divided into a number of parts.

First suppose that $a<f(a) \Lambda g(a)$; without loss of generality we may suppose that for $a<x<b=f(a) \Lambda g(a)$ there is a $z, a<z<x$ with $f(z) \notin M(z)$. Thus let $a<z_{1}<b_{1}<b$ with $f\left(z_{1}\right) \notin M\left(z_{1}\right)$. Then $b_{1} \in f\left[a, z_{1}\right]$. Say $a<y_{1}<z_{1}$ and $f\left(y_{1}\right)=b_{1}$. But then there is a $z_{2}, a<z_{2}<y_{1}$ with $f\left(z_{2}\right) \notin M\left(z_{2}\right)$. Thus $f\left[a, z_{2}\right]$ also contains $b_{1}$ which contradicts the assumption that $f^{-1}\left(b_{1}\right)$ is arcwise connected.

Next we assume that $a \neq f(a)$ and $a \neq g(a)$, and that $a=$ $f(a) \Lambda g(a)$. For each $i=1,2$, let $B_{i}$ be the branch at a containing $x_{1}=f(a)$ and $x_{2}=g(a)$ respectively. Since $f$ and $g$ commute $f\left(x_{2}\right)=$ $g\left(x_{1}\right)$ and hence, either $g\left(x_{1}\right) \notin B_{2}$ or $f\left(x_{2}\right) \notin B_{1}$. Say $f\left(x_{2}\right) \notin B_{1}$. Then $a \in f\left[a, x_{2}\right]$. By Lemmas 3 and 4 there is a fixed point $y_{1}$ of $f$ in $B_{1}$ such that the only $f$-fixed point in $\left[a, y_{1}\right]$ is $y_{1}$. Next note that $f g\left(y_{1}\right)=g f\left(y_{1}\right)=g\left(y_{1}\right)$ and so $g\left(y_{1}\right)$ is also a fixed point of $f$. Further, if $y_{2}=g\left(y_{1}\right) \notin B_{1}$, then $a \in\left[y_{2}, y_{1}\right]$ and thus $a \in f\left[y_{2}, y_{1}\right]$. This leaves two possibilities: either $y_{2} \in B_{1}$ or $y_{2} \in B_{2}$ for otherwise $a \in f^{-1}(a)$ which is a contradiction. So suppose $y_{2} \in B_{1}$ and let $b=y_{1} A y_{2}$. Then if $f(b) \notin M(b), b \in f\left[b, y_{1}\right] \cap f\left[b, y_{2}\right]$ and so $b \in f^{-1}(b)$ which contradicts the choice of $y_{1}$. Thus $f(b) \in M(b)$. Then $g(b) \notin M(b)-b$ follows from the maximality of $a$. Next set $y_{3}=g\left(y_{2}\right)$. If $y_{3} \in M(b)$ we have $b \in g\left[b, y_{1}\right] \cap g\left[b, y_{2}\right]$ which is a contradiction. Hence, $y_{3} \notin$ $M(b)$. Note $f\left(y_{3}\right)=y_{3}$. So we have $b \in f\left[y_{3}, b\right]$ and either $b \in f\left[b, y_{1}\right]$ or $b \in f\left[b, y_{2}\right]$ which is another contradiction.

We still have the subcase $y_{2} \in B_{2}$ to consider. By Lemma 3 we may assume that $f$ does not have another fixed point in $\left[a_{1}, y_{2}\right]$. Then set $y_{3}=g\left(y_{2}\right)$. As above either $y_{3} \in B_{1}$ or $y_{3} \in B_{2}$. In either of 
these cases we can obtain the same contradiction as in the case where $y_{2} \in B_{1}$. Hence, the argument for $f(a) \neq a \neq g(a)$ and $f(a) \Lambda g(a)=$ $a$ is concluded.

Finally, assume $f(a)=a$ and $a<g(a)=y_{1}$. Since $y_{1}$ is a fixed point of $f, g\left(y_{1}\right) \notin M\left(y_{1}\right)$. Thus there is a $g$-fixed point $x_{1} \in M(a)-$ $M\left(y_{1}\right)$. Let $b=x_{1} \Lambda y_{1}$. Then $a \leqq b<y_{1}$ and so let $c$ be such that $b<c<y_{1}$. Now if $x_{2}=f\left(x_{1}\right) \notin M(a)$, then $c \in g\left[x_{2}, a\right]$ and $c \in g\left[a, x_{1}\right]$ which is a contradition since $a \notin g^{-1}(c)$. Thus $x_{2} \in M(a)$ and $x_{2} \notin M\left(x_{1}\right)$. From Lemma 3 we may assume that $x_{1}$ is the only $g$-fixed point in $\left[a, x_{1}\right]$. Now let $d=x_{1} \Lambda x_{2}$. As in the previous arguments, applied to $g$ in this case, $f(d) \in M(d)$. Finally we set $x_{3}=f\left(x_{2}\right)$ and the same arguments as above give the same contradiction. Thus we conclude that $a$ is a fixed point of both $f$ and $g$.

\section{REFERENCES}

1. W.J. Gray, A fixed point theorem for commuting monotone functions, Canad. J. Math., 21 (1969), 502-504.

2. W. J. Gray and C. M. Smith, Common fixed points of commuting mappings, Proc. Amer. Math. Soc., 53 (1975), 223-226.

3. J. K. Harris, Order structures for certain acyclic topological spaces, Thesis, University of Oregon, Eugene, Oregon, 1962.

4. T. B. Muenzenberger and R. E. Smithson, Fixed point structures, Trans. Amer. Math. Soc., 184 (1973), 153-173.

5. R. E. Smithson, Fixed point theorems for certain classes of multifunctions, 31 (1972), 595-600.

6. G. S. Young, Jr., The introduction of local connectivity by change of topology, Amer. J. Math., 68 (1946), 479-494.

Received July 14, 1978 and in revised form February 15, 1979. This paper was written while the author was a visiting professor of mathematics at California State University, Chico.

UNIVERSITY OF WYOMING

LARAMIE, WY 82071 



\section{PACIFIC JOURNAL OF MATHEMATICS}

\section{EDITORS}

Donald BABBITT (Managing Editor)

University of California

Los Angeles, CA 90024

HUGo RossI

University of Utah

Salt Lake City, UT 84112

C. C. MOORE and ANDREW OGG

University of California

Berkeley, CA 94720

\section{J. DuGUNDJI}

Department of Mathematics

University of Southern California

Los Angeles, CA 90007

R. FINN and J. Milgram

Stanford University

Stanford, CA 94305

ASSOCIATE EDITORS
E. F. BECKENBACH
B. H. NeumanN
F. WOLF
K. YoSHIDA

\section{SUPPORTING INSTITUTIONS}

\author{
UNIVERSITY OF BRITISH COLUMBIA \\ CALIFORNIA INSTITUTE OF TECHNOLOGY \\ UNIVERSITY OF CALIFORNIA \\ MONTANA STATE UNIVERSITY \\ UNIVERSITY OF NEVADA, RENO \\ NEW MEXICO STATE UNIVERSITY \\ OREGON STATE UNIVERSITY \\ UNIVERSITY OF OREGON
}

\author{
UNIVERSITY OF SOUTHERN CALIFORNIA \\ STANFORD UNIVERSITY \\ UNIVERSITY OF HAWAII \\ UNIVERSITY OF TOKYO \\ UNIVERSITY OF UTAH \\ WASHINGTON STATE UNIVERSITY \\ UNIVERSITY OF WASHINGTON
}

The Supporting Institutions listed above contribute to the cost of publication of this Journal, but they are not owners or publishers and have no responsibility for its content or policies.

Mathematical papers intended for publication in the Pacific Journal of Mathematics should be in typed form or offset-reproduced, (not dittoed), double spaced with large margins. Please do not use built up fractions in the text of the manuscript. However, you may use them in the displayed equations. Underline Greek letters in red, German in green, and script in blue. The first paragraph or two must be capable of being used separately as a synopsis of the entire paper. Please propose a heading for the odd numbered pages of less than 35 characters. Manuscripts, in triplicate, may be sent to any one of the editors. Please classify according to the scheme of Math. Reviews, Index to Vol. 39. Supply name and address of author to whom proofs should be sent. All other communications should be addressed to the managing editor, or Elaine Barth, University of California, Los Angeles, California, 90024.

50 reprints to each author are provided free for each article, only if page charges have been substantially paid. Additional copies may be obtained at cost in multiples of 50 .

The Pacific Journal of Mathematics is issued monthly as of January 1966. Regular subscription rate: $\$ 84.00$ a year (6 Vols., 12 issues). Special rate: $\$ 42.00$ a year to individual members of supporting institutions.

Subscriptions, orders for numbers issued in the last three calendar years, and changes of address should be sent to Pacific Journal of Mathematics, P.O. Box 969, Carmel Valley, CA 93924, U.S.A. Older back numbers obtainable from Kraus Periodicals Co., Route 100, Millwood, NY 10546.

PUBLISHED BY PACIFIC JOURNAL OF MATHEMATICS, A NON-PROFIT CORPORATION

Printed at Kokusai Bunken Insatsusha (International Academic Printing Co., Ltd.). 8-8, 3-chome, Takadanobaba, Shinjuku-ku, Tokyo 160, Japan.

Copyright (C) 1979 by Pacific Journal of Mathematics Manufactured and first issued in Japan 


\section{Pacific Journal of Mathematics}

\section{Vol. 82 , No. 2 \\ February, 1979}

Krishnaswami Alladi and Paul Erdős, On the asymptotic behavior of large prime

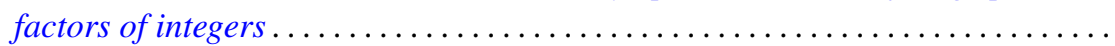

Alfred David Andrew, A remark on generalized Haar systems in $L_{p}$,

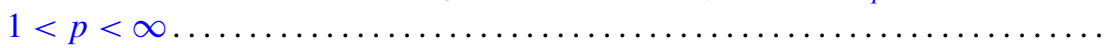

John M. Baker, A note on compact operators which attain their norm . . ........

Jonathan Borwein, Weak local supportability and applications to

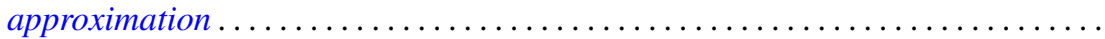

Tae Ho Choe and Young Soo Park, Wallman's type order compactification ........

Susanne Dierolf and Ulrich Schwanengel, Examples of locally compact

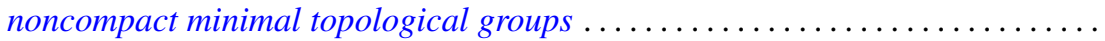

Michael Freedman, A converse to (Milnor-Kervaire theorem) $\times R$ etc. . . . . . . .

George Golightly, Graph-dense linear transformations ..................

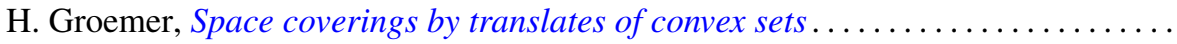

Rolf Wim Henrichs, Weak Frobenius reciprocity and compactness conditions in

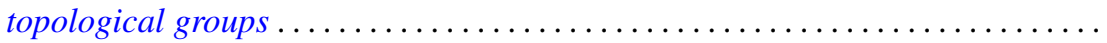

Horst Herrlich and George Edison Strecker, Semi-universal maps and universal

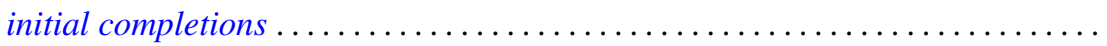

Sigmund Nyrop Hudson, On the topology and geometry of arcwise connected,

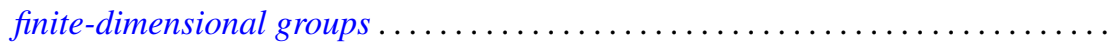

K. John and Václav E. Zizler, On extension of rotund norms. II .............

Russell Allan Johnson, Existence of a strong lifting commuting group of transformations. II.

Bjarni Jónsson and Ivan Rival, Lattice varieties covering the smallest nonmodular variety

Grigori Abramovich Kolesnik, On the order of Dirichlet L-functions .

Robert Allen Liebler and Jay Edward Yellen, In search of nonsolvable groups of

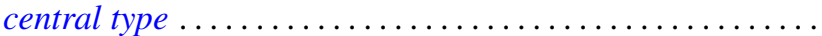

Wilfrido Martínez T. and Adalberto Garcia-Maynez Cervantes, Unicoherent plane Peano sets are $\sigma$-unicoherent ...

M. A. McKiernan, General Pexider equations. I. Existence of injective

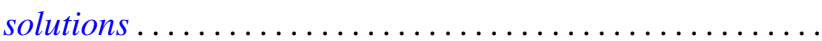

M. A. McKiernan, General Pexider equations. II. An application of the theory of webs.

Jan K. Pachl, Measures as functionals on uniformly continuous functions . .

Lee Albert Rubel, Convolution cut-down in some radical convolution algebras ...

Peter John Slater and William Yslas Vélez, Permutations of the positive integers

with restrictions on the sequence of differences. II . . .

Raymond Earl Smithson, A common fixed point theorem for nested spaces ....

Indulata Sukla, Generalization of a theorem of McFadden .... . . .

Jun-ichi Tanaka, A certain class of total variation measures of analytic measures.

Kalathoor Varadarajan, Modules with supplements .............. 